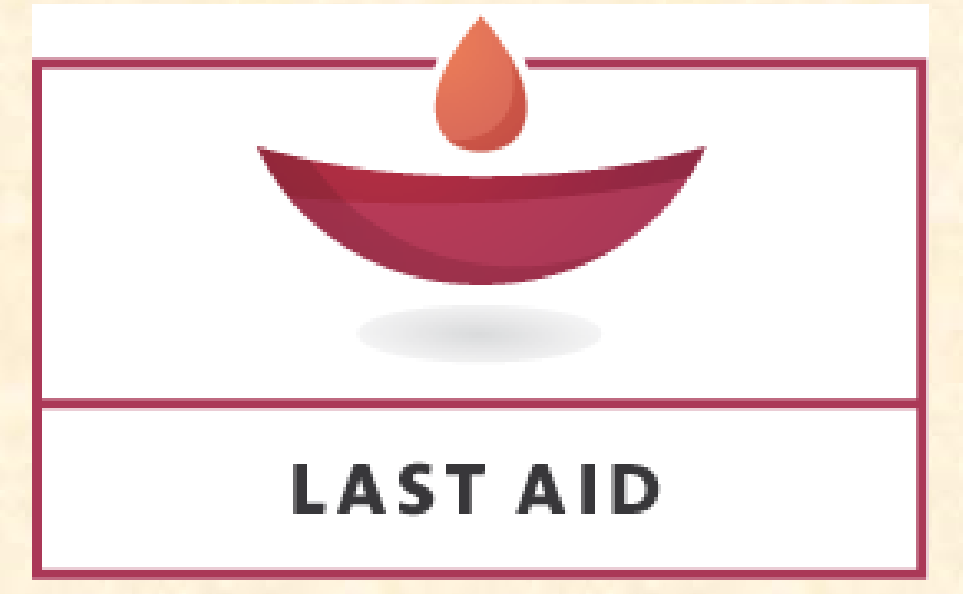

\title{
Last Aid International - Implementation of an international working group on Last Aid courses for the public
}

\author{
Bollig G
}

${ }^{1}$ Palliative Care Team, Medical Department Sønderborg/Tønder, South Jutland Hospital, Sønderborg, Denmark

${ }^{2}$ Palliative Care research group, Medical Research Unit, Institute of Regional Health Research, University of Southern Denmark

${ }^{3}$ Last Aid International, Schleswig, Germany georg.bollig@rsyd.dk

\section{Aims:}

Although most people want to die at home many people die in institutions. Last Aid Courses can serve as basic palliative care education for the public and compassionate communities and may enhance the possibility of dying at the preferred place.

Pilot courses in Norway, Denmark and Germany have shown the feasibility and acceptance of the course.

The described project was undertaken as a part of the EUPCA Leadership Course 2017-2019 organized by the European Palliative Care Academy (1). It was designed as step 2 of the international project Last Aid International - the Last Aid Movement.

The main goals of the current project were to establish an international Last Aid working group with participants from 6-10 countries and to reach consensus on the curriculum for an international Last Aid course.

\section{Methods:}

Associations engaged in palliative care in European countries were invited to participate in an international working group. A variety of national organisations such as palliative care organisations, health-services, the church or other national organisations were invited. Participating countries send two delegates as participants to the meetings of the working group. All working group members reviewed the existing Last Aid Course curriculum that had been established and pilot-tested by Bollig et al. $(2,3)$

\section{Results:}

Consensus on an international Last Aid Course curriculum was established during a two-day meeting of the working group consisting of experts from different professions working within palliative care from seven different countries. The adaptation of the international presentation is finished. Work with translation into different languages and education of Last Aid course instructors in the participating countries is ongoing. At present national organisations from ten countries participate in the international Last Aid working group. In the meantime the International Last Aid working group is expanding further.

The EAPC has established a taskforce "Last Aid - Providing Palliative Care Education for Citizens" (3) to review the literature and develop an overview of the models for dissemination of palliative care knowledge to the public; to map education needs of palliative care in local communities in European countries; and to develop a consensus based curriculum and content for an international Last Aid course.

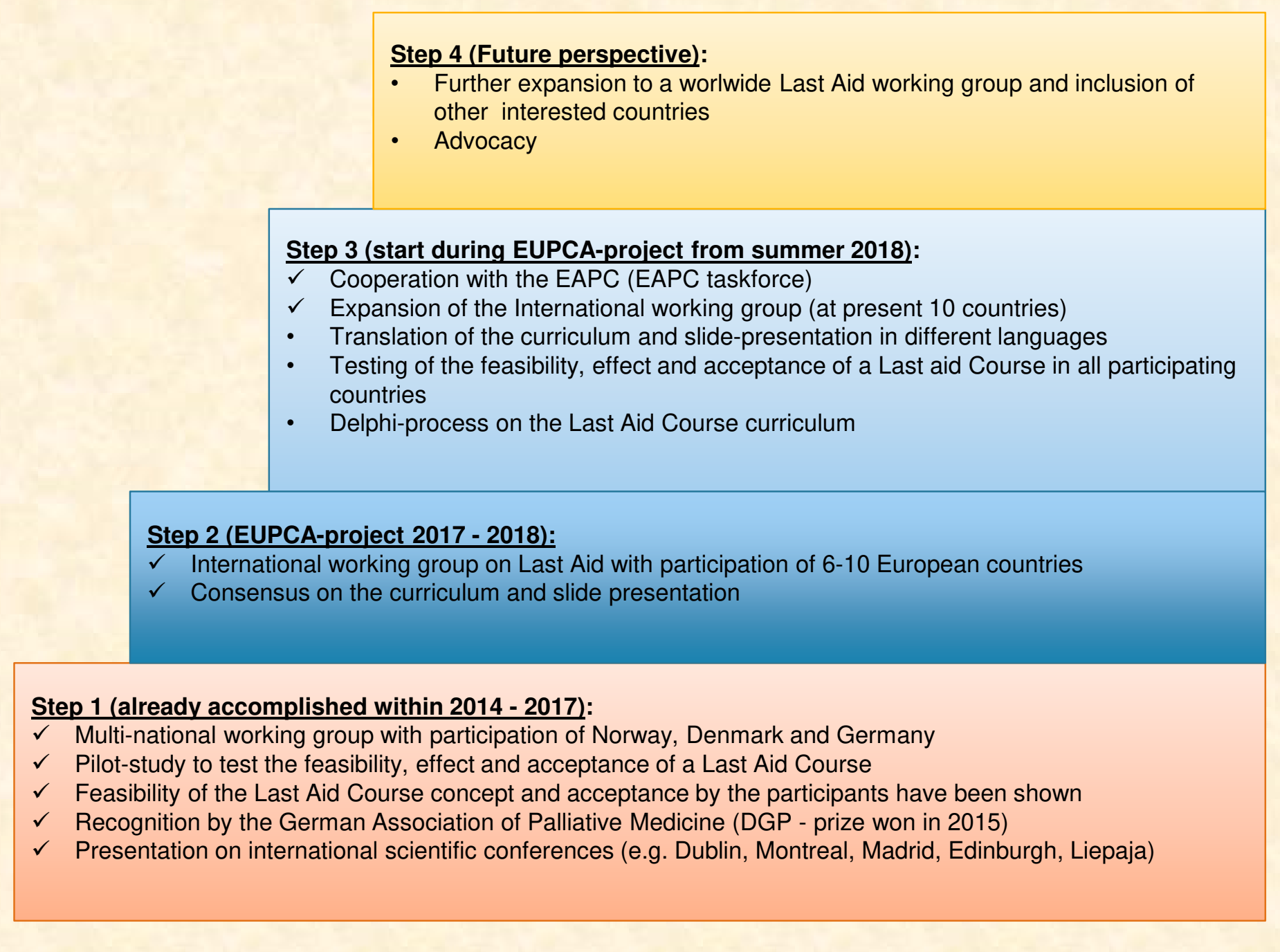

Fig. 1: The four steps of the international project Last Aid International - the Last Aid Movement

\section{Conclusions:}

The first experiences with Last Aid courses are very promising. The formation of an international Last Aid working group and consensus on a curriculum has been achieved in 2018. Research on the implementation and effect of Last Aid courses and a wider distribution and inclusion of other countries is ongoing. Meetings of the working group in order to evaluate and adapt the curriculum will be held with regular intervals of 1-2 years. In September 2019 the First International Last Aid congress will take place in Sønderborg, Denmark. More Information about Last Aid courses can be found on the project homepage

\section{References:}

1. EUPCA Leadership Course - Georg Bollig https://www.eupca.eu/georg-bollig/

2. Bollig G, Kuklau N. Der Letzte Hilfe Kurs - ein Angebot zur Verbesserung der allgemeinen ambulanten Palliativ-versorgung durch Information und Befähigung von Bürgerinnen und Bürgern. Z Palliativmed 2015; 16:210-216.

3. Bollig G, Heller A. The last aid course - a simple and effective concept to teach the public about palliative care and to enhance the public discussion about death and dying. Austin Palliat Care 2016; 1(2): 1010.

4. Bollig G, Brandt F, Ciurlionis M, Knopf B. Last Aid Course. An Education For All Citizens and an Ingredient of Compassionate Communities. Healthcare 2019, 7, 19; doi:10.3390/healthcare7010019

5. EAPC Taskforce Last Aid https://www.eapcnet.eu/eapc-groups/task-forces/last-aid

6. Letzte Hilfe Deutschland www.letztehilfe.info

7. Last Aid www. lastaid.info

\section{SDU:-}

UNIVERSITY OF SOUTHERN DENMARK 